\title{
Conjoint Analysis: A Study on UOG Faculty Service
}

\author{
${ }^{1}$ Zahoor Ahmad, ${ }^{2}$ Sadaf Nawaz \\ ${ }^{1,2}$ Department of Statistics, University of Gujrat, Pakistan
}

\begin{abstract}
A good teaching service of faculty members is the key to success of universities regarding their good product of students. In this research paper our major objective is to find important attributes and their levels of good service of faculty members. We focus on student's choice because service of faculty member plays a vital role on the performance of students. In our case especially we want to investigate student's preferences toward attributes and their levels of service. We collect data from University of Gujrat by using two types of questionnaires. One questionnaire was for Full Profile Conjoint Analysis and other for Choice-Based Conjoint Analysis. Full Profile Conjoint Analysis technique we used four attributes with two levels each. The attributes with their levels are Qualification (MSc/MA and M.Phil/PhD), Teaching Methodology (Verbal \& White Board and Multimedia), Lecture Material (Net \& Lecture Notes and Books) and Gender (Male and female). From the results of Full Profile Conjoint Analysis we conclude that students give first importance to Qualification, almost same importance to Teaching Methodology and Lecture Material. They give least importance to gender of faculty member. According to our results regarding levels of attributes, student's desire to study from M. Phil. /Ph. D. female faculty member and her teaching methodology should be based on verbal communication and white board and she also provide lecture notes.

Choice-Based Conjoint Analysis we use six attributes with three levels of each. The attributes and their levels are qualification (MA/MSc, M.Phil and PhD), Behavior (Normal Behavior, Lenient Behavior and Friendly Behavior), Teaching Experience (1-3 years, 4-6 years and 7 years \& above), Teaching Methodology (Multimedia, White Board and Verbal \& White Board), Lecture Material (Books, Notes and Net \& Notes) and No. of Quizzes (2 Quizzes, 3 Quizzes and 4 Quizzes). From the results of Choice-Based Conjoint Analysis we conclude that attribute "Qualification" is most important in all service attributes. So Qualification of faculty member plays important role for selecting a teacher. Students give second importance to behavior of the teacher with students, third importance to Teaching Methodology, fourth importance to Lecture Material, fifth importance to No. of quizzes and sixth importance to Teaching Experience.

Students give preference to M. Phil. faculty member with 4-6 years experience of teaching and they want friendly behavior from their teacher. The teaching methodology should be based on verbal communication and white board. He/she provide lecture notes and take 2 Quizzes.
\end{abstract}

\section{INTRODUCTION}

Services of faculty members play a vital role in the success of universities, because the academic performance of students is mostly based on the good service of faculty member. Success of university performance depend upon sincere service of faculty members who have a clear perception of how to combine the elements of teaching, research, and service in a way that makes the best use of the time and resources available. Service includes classroom observation, lecture material, mid-semester feedback from students, methodology of conveying lecture, behavior with students and multiple office visits. Faculty members are expecting to make substantive contributions to the learning of their students, as well as to their fields and the university. Faculty members are more likely to make substantive contributions when they have well defined goals and a specific plan for reaching towards goals.

Faculty contributes to the attainment of the broad objectives of the university: teaching, research, and community service. Faculty provides academic guidance to students and extends the frontiers of knowledge through research and publication. This makes faculty members' need for information inevitable. Much of this information is acquired, processed, and disseminated through the university library which has been variously described as "the heart of the institution" [1], "a place where books and users interact together for the transmission of civilization and cultivation of human beings"

It is important to note that successful faculty performance is dynamic in nature. The relative amount of time that a faculty member devotes to teaching, research, and service can vary over time.

It is explicable that faculty members should provide proper services to students while dealing with the students. Faculty members must respond without hesitation to a student's request. Intentionally or unintentionally they try to hold them in their control and unjustifiably they do not fulfill the academic requirements of their students. It is extremely complicated situation and it need to be paid a great attention for the solution. The manners in which faculty members attain some measures of control in this situation help understand the relative responsibilities of theirs. 
Sometimes faculty members should try to ease the students instead of making them stressful or putting burden on them by assigning them a lot of work. They should provide them enough material which can help them in understanding a topic. Teachers should use the teaching techniques which can have a positive effect on their learning.

Teachers should have better Communication skills, punctuality, should be cooperative and qualified to what he is teaching. They should teach the students by using easy language and should adapt a level of students' reception. Their attitude should be encouraging so that students can show interest in studies. Faculty members must have an influential impact on the personality development of the students. When students face problems in an institution, faculty members are among the first who can solve their problems. Attitude of faculty members can play an important role in the academic achievement, intellectual perception and personal development as well as learning process of the students.

In our research we focus to find important attributes of good service of faculty members. We are focusing on student's choice because service of faculty member plays a vital role on the performance of students. The possible objective can be written as

1. To check the attributes and their levels which have played an important role in good service of faculty members?

2. To find a combination of attributes and their levels of good service of faculty member.

\section{LITERATURE REVIEW}

Twelve accommodations suggested in different studies that can be provided by faculty are: (i) untimed tests; (ii) readers for objective exams; (iii) essay exams instead of objective exams; (iv) taking exams in a separate room with a proctor; (v) rephrasing questions; (vi) oral, taped, or typed responses to exams instead of written exams; (vii) alternative methods for demonstrating mastery; (viii) avoiding complex sentences, double negatives; (ix) alternatives to computer scored sheets; (x) adequate lined paper for poor handwriting; (xi) analyzing process and final solution; and (xii) allowing multiplication table, calculator, and desk reference for examinations see [2] for reference.

Non-tenure track faculty had a significantly better attitude and higher level of understanding for the need to provide accommodations. Similarly part-time faculty reported a significantly better understanding than full time faculty (see [3]).

A study in [4] showed that acceptance of disabilities could be enhanced by cooperative work in the classroom and by others' modeling acceptance through friendliness and assisting with special accommodations required in the classroom or on campus. A recurring theme in the response of the subjects was that education about disabilities was needed.

In [5] it is concluded that the response as faculty with doctorate and faculty without doctorate and further it is found that faculty without a doctorate had more positive attitude and were more willing to provide accommodations. The male faculty more than female faculty indicated that they had made accommodations in their classes (see [6]).

Regarding the variable of gender, some inconsistent findings were obtained. Male faculty indicated that they had more teaching experience with some groups of students with disabilities and expressed an overall stronger willingness to provide accommodations than did female faculty. On the other hand, female faculty indicated that they had more training in the area of disabilities, more knowledge of legislation, and expressed more willingness to participate in additional training. The question as to why more extensive previous training and increased knowledge among female faculty were not translated into a stronger willingness to make needed accommodations is difficult to answer. Several previous studies have also shown that female faculty held more favorable attitudes and had more knowledge about disabilities (see [7], [8] and [9]).

\section{METHODOLOGY}

3.1 Sample Size Determination for Conjoint Methodologies:

The sample size required for the conjoint analysis is debatable because there is no definite rule to follow. Before we calculate the sample size for a conjoint analysis, we need to calculate the number of parameters. Usually the total number of parameters is equal to the total number of levels (all levels for all attributes combined) minus the total number of attributes plus one.

For example, in this study in full profile analysis we have four attributes with two levels for each. We would have a total of $8(2 \times 4)$ levels. We then have 5 parameters $(8-4+1)$. The rule of thumb for the ratio of the number of parameters to the number of respondents is between five and 10.So we then need at least 25 students (5 parameters x 5) to complete the study [10].But we could not apply this rule on Choice Based Conjoint Analysis in this study because we have limitations of software. We have demo version. We chose only five students for Choice Based Conjoint Analysis. 
3.2 Data Collection Tool:

We use two types of questionnaires to collect the data and generate our results. In Full Profile Conjoint Analysis we take four attributes with two levels so we make 16 profiles .We make full profile questionnaire in SPSS 16.0 software. We give 16 combination of faculty services to respondents for rank between 1 to 16 . In Choice Based Conjoint analysis (CBC) we give a set of whole profiles to respondent to choose one of them. We give ten tasks to a respondent for preference. We take six attributes for $\mathrm{CBC}$ questionnaire.

\subsection{Sampling Technique:}

In this study we have used convenient sampling for Choice-Based Conjoint Analysis. We use stratified random sampling, for the data collection of Full Profile Conjoint Analysis.

\subsubsection{Sample Characteristics for full profile:}

A profile of the sample is presented in below in Table 1 table respondent are fairly representative of the University of Gujrat population of both programs (BS/MSc). We collect data from second (28\%), fourth (60\%), fifth $(8 \%)$ and sixed semester $(4 \%)$, because when we collect data these semesters are running only. Girls are $56 \%$ and boys are $44 \%$ of age between $18-24$. We take $4 \%$ students from English department, $8 \%$ from Sociology department, $12 \%$ from Computer Science Information Technology department ( CSIT), $4 \%$ from Mass and Media Communication (MCM), 4\% from Zoology department, 12\% from Bachelor in Business Administration (BBA), $4 \%$ from Electrical Engineering, 4\% from Physics, 12\% from Statistics, 4\% from Master in Population Science, 12\% from Economics, $4 \%$ from Master in Business Administration (MBA), $4 \%$ from Chemistry, 4\% from Mathematics, $4 \%$ from Psychology and 4\% from Fine Arts department. We can see our sample profile below.

TABLE-1: Sample Profile

\begin{tabular}{|c|c|c|c|c|c|}
\hline \multicolumn{6}{|c|}{ Gender } \\
\hline Male & & $44 \%$ & Female & $56 \%$ & \\
\hline \multicolumn{6}{|c|}{ Program } \\
\hline Master & & $40 \%$ & BS & \multicolumn{2}{|l|}{$60 \%$} \\
\hline \multicolumn{6}{|c|}{ Department } \\
\hline English & $4 \%$ & CSIT & $12 \%$ & MCM & $4 \%$ \\
\hline Sociology & $8 \%$ & BBA & $12 \%$ & Electrical Engineering & $4 \%$ \\
\hline Zoology & $4 \%$ & Statistics & $12 \%$ & MPS & $4 \%$ \\
\hline Physics & $4 \%$ & Economics & $12 \%$ & MBA & $4 \%$ \\
\hline MCM & $4 \%$ & Mathematics & $4 \%$ & Psychology & $4 \%$ \\
\hline Chemistry & $4 \%$ & Fine Arts & $4 \%$ & & \\
\hline \multicolumn{6}{|c|}{ Semester } \\
\hline Second Semester & $28 \%$ & Fourth Semester & $60 \%$ & Fifth Semester & $8 \%$ \\
\hline Sixth Semester & $4 \%$ & & & & \\
\hline
\end{tabular}

\subsection{Data Analysis Technique:}

Student's choices for service of faculty member or service attributes can be evaluated using conjoint analysis.

\subsubsection{The Nature of Conjoint Analysis:}

The word Conjoint is a mixture of two words Consider Jointly. So the name "Conjoint Analysis" implies the study of the joint effects of different levels of a product or products and it is also a combination of different Statistical tools.

"Conjoint analysis is a multivariate technique used specifically to understand how respondents develop preferences for products or services. It is based on the simple premise that consumers evaluate the value of a product or service by combining the separate amounts of value provided by each attribute"[11]. It is not a data analysis procedure like factor analysis or cluster analysis. It must be regarded as a type of "thought experiment" designed to show how various elements of products or services (price, brand, style) predict customer preferences for a product or service [12]. Conjoint analysis as "a method for deriving the utility values that consumers attach to varying levels of a product's attributes" [13] .conjoint analysis as “...conjoint measurement, which relies on the ability of respondents to make judgments about stimuli (Concept)." These stimuli represent some predetermined combinations of attributes, and during a laboratory experiment, respondents are asked to make judgments about their preferences for various attribute combinations. The basic aim, therefore, is to determine the features they most prefer. The value of conjoint analysis lies in the fact that it estimates how much each of 
these attributes is valued, and "the word conjoint has to do with the notion that the relative values of things considered jointly can be measured when they might not be measurable if taken one at a time." We brief below only two types of conjoint analysis which we used for analysis in this research [14].

\subsubsection{Full Profile Conjoint Analysis:}

In full profile techniques each respondent sees a complete set of full profile prop cards. After sorting the card into ordered categories the respondent rate each card on a 0 to 100 likelihood of purchase scale. Traditional full-profile (FP) conjoint was reported as a popular method. In general, we believe traditional FP conjoint is an excellent approach when the number of attributes is around six or fewer.

\subsubsection{Choice Based conjoint Analysis:}

A particular type of conjoint analysis, experimental choice or "choice-based conjoint" (CBC) analysis, was developed in the 1980s in response to industry desires to consider explicit competitive contexts [15]. More recently, the use of $\mathrm{CBC}$ by marketing research practitioners has experienced significant growth (relative to ratings-based conjoint analysis), as more companies want to understand how people make choices. Rather than rate each product concept/profile one at a time on a measure of attractiveness or likelihood of purchase ("ratings-based" conjoint), respondents are asked to choose, i.e., make a preference judgment, between a series of two or more competitive product profiles. This approach to measuring preferences combines discrete choice responses, a logit model that is applied to these responses, and a fractional factorial design in order to minimize the number of choices respondents have to make. Unlike more traditional conjoint software, CBC analysis produces aggregate part-worth or utilities for each attribute and level; it does not generate a set of individual utilities for each respondent. This shortcoming was overcome in the present study by using Hierarchical Bayes (HB) to estimate part-worths at the individual level.

\subsubsection{Assumptions of Conjoint Analysis:}

1. Conjoint analysis assumes perfect information. In the conjoint interview, respondents are educated about available brands and features. In the real world, unclear attributes have less chance of being purchased. Conjoint analysis cannot fully account for differences in awareness developed through advertising and promotion.

2. Conjoint analysis assumes that all products and services are equally available. One brand is as conveniently selected as another in a conjoint interview.

3. Respondents might not accurately reflect potential buyers. Many will not have the interest, authority, or ability to purchase.

4. Results from conjoint analysis reflect the potential market acceptance of products and services, given proper promotion, distribution, and time.

\section{RESULT AND DISCUSSION}

In this section we have discussed the results of both types of conjoint analyses. Let, start with full profile conjoint analysis and then choice based conjoint analysis.

\subsection{Full Profile Conjoint Analysis:}

TABLE-2: Full Profile Analysis: Overall Utility for all Respondents

\begin{tabular}{|c|c|c|c|c|c|c|c|c|c|}
\hline Attributes & \multicolumn{2}{|c|}{ Qualification } & \multicolumn{2}{|c|}{ Methodology } & \multicolumn{2}{|c|}{$\begin{array}{l}\text { Lecture } \\
\text { Material }\end{array}$} & \multicolumn{2}{|c|}{ Gender } & Constant \\
\hline Levels & $\begin{array}{l}\text { M.A/ } \\
\text { MSC }\end{array}$ & M.Phil./PhD. & $\begin{array}{c}\text { Verbal } \\
\& \\
\text { White } \\
\text { Board }\end{array}$ & Multimedia & $\begin{array}{c}\text { Net } \\
\& \\
\text { Notes }\end{array}$ & Books & Male & Female & \\
\hline $\begin{array}{l}\text { Over all } \\
\text { Utility }\end{array}$ & $\begin{array}{c}- \\
0.192\end{array}$ & 0.192 & -0.365 & -0.730 & $\begin{array}{c}- \\
0.115\end{array}$ & $\begin{array}{c}- \\
0.230\end{array}$ & 0.255 & 0.510 & 8.835 \\
\hline
\end{tabular}

Consistent with theories of utility maximization and student rationality, Table 2 shows that the most preferred faculty member (i.e., the one with the greatest overall utility), the preference of all respondents for faculty member is M. Phil. /Ph. D., Verbal and White Board, Notes and Female faculty member with utility .192,-..365, -.115 and 0.510 respectively. So students desire to study from M. Phil. /Ph. D. female faculty member. She delivers her lecture verbally and by the help of white board. Students need notes from their teacher on study topic. 
Conjoint Analysis: A study on UOG faculty service

TABLE-3: Overall relative importance of attributes for all respondents

\begin{tabular}{|c|c|c|c|c|}
\hline Attribute & Qualification & Methodology & Lecture Material & Gender \\
\hline $\begin{array}{c}\text { Over all } \\
\text { Importance }\end{array}$ & $27.362 \%$ & $25.767 \%$ & $25.896 \%$ & $20.975 \%$ \\
\hline
\end{tabular}

Table 3 provides a measure of the relative importance of each factor known as an importance score or value. The larger a percentage is for an attribute, the more weight that attribute has in your overall decision-making process. With these percentages, you can also calculate how much influence an attribute has over another by dividing an attribute's score by a target's score.

The overall importance for all the respondents for Qualification, Methodology, Lecture Material and Gender is $27.362 \%, 25.767 \%, 25.896 \%$ and $20.975 \%$ respectively. It means that students give more importance to Qualification, almost same importance to Methodology and Lecture Material. They give least importance to gender of faculty member.

TABLE-4: Test of Correlation between observed and expected preferences

\begin{tabular}{|c|c|c|}
\hline Respondent & Kendall's tau & p-value \\
\hline Over all & 0.349 & 0.032 \\
\hline
\end{tabular}

Table 4 contains the Kendall's tau measure of correlation between observed and estimated preferences. The value of overall respondents shows that there is correlation between observed and estimated preferences.

4.2 Choice-Based Conjoint Analysis:

TABLE-5: Attribute Importance

\begin{tabular}{|c|c|c|c|c|}
\hline Attribute & Levels & Utilities & Utility Range & Importance \\
\hline \multirow{3}{*}{ Qualification } & PhD. & -1.45886 & \multirow{3}{*}{3.965} & \multirow{3}{*}{$33.75 \%$} \\
\hline & M.Phil. & 2.50607 & & \\
\hline & MA/MSc. & -1.04720 & & \\
\hline \multirow{3}{*}{ Behavior } & Friendly Behavior & 1.13612 & \multirow{3}{*}{2.35539} & \multirow{3}{*}{$20.05 \%$} \\
\hline & Lenient Behavior & 0.08315 & & \\
\hline & Normal Behavior & -1.21927 & & \\
\hline \multirow{3}{*}{$\begin{array}{l}\text { Teaching } \\
\text { Experience }\end{array}$} & 7 year and above & 0.39287 & \multirow{3}{*}{0.98039} & \multirow{3}{*}{$8.345 \%$} \\
\hline & 4-6 years & 0.19465 & & \\
\hline & $1-3$ years & -0.58752 & & \\
\hline \multirow{3}{*}{ Methodology } & Verbal and White Board & 1.31213 & \multirow{3}{*}{2.23103} & \multirow{3}{*}{$18.99 \%$} \\
\hline & White Board & -0.39324 & & \\
\hline & Multimedia & -0.91890 & & \\
\hline \multirow{3}{*}{ Lecture Material } & Net and Notes & -0.64904 & \multirow{3}{*}{1.14022} & \multirow{3}{*}{$9.71 \%$} \\
\hline & Notes & 0.15786 & & \\
\hline & Books & 0.49118 & & \\
\hline \multirow{3}{*}{ No. of Quizzes } & 2 Quizzes & 0.45561 & \multirow{3}{*}{1.07577} & \multirow{3}{*}{$9.16 \%$} \\
\hline & 3 Quizzes & -0.62016 & & \\
\hline & 4 Quizzes & 0.16456 & & \\
\hline
\end{tabular}

Table 5 contains the Attribute importance. This measure is very important. We observe that Attribute "Qualification" is most important in all service Attribute. It takes 33.75\% importance in a service of faculty members Concept. So Qualification plays important role for selecting a teacher for study a course. Behavior of the teacher with students, Lecture Methodology, Lecture Material, Teaching Experience and No. of quizzes have importance $20.05 \%, 18.99 \%, 9.71 \%, 8.345 \%$ and $9.16 \%$. 
Conjoint Analysis: A study on UOG faculty service

TABLE A-6: Total Utility of each concept of every Task of all Respondents

\begin{tabular}{|c|c|c|c|c|c|}
\hline Task & Concept & Utility & Task & Concept & Utility \\
\hline \multirow{3}{*}{1} & 1 & -2.8261 & \multirow{3}{*}{6} & 1 & -1.85159 \\
\hline & 2 & 1.92833 & & 2 & 1.73854 \\
\hline & 3 & 0.89778 & & 3 & 0.11306 \\
\hline \multirow{3}{*}{2} & 1 & 2.32905 & \multirow{3}{*}{7} & 1 & -0.08516 \\
\hline & 2 & -4.25992 & & 2 & 2.67666 \\
\hline & 3 & 1.93088 & & 3 & -2.59149 \\
\hline \multirow{3}{*}{3} & 1 & -1.35414 & \multirow{3}{*}{8} & 1 & 1.70468 \\
\hline & 2 & 0.36912 & & 2 & 0.72717 \\
\hline & 3 & 0.98503 & & 3 & -2.43184 \\
\hline \multirow{3}{*}{4} & 1 & -5.45375 & \multirow{3}{*}{9} & 1 & 2.39542 \\
\hline & 2 & -0.30868 & & 2 & -4.31353 \\
\hline & 3 & 5.76244 & & 3 & 1.91812 \\
\hline \multirow{3}{*}{5} & 1 & -2.23362 & \multirow{3}{*}{10} & 1 & -1.97456 \\
\hline & 2 & 5.02254 & & 2 & 3.9045 \\
\hline & 3 & -2.78891 & & 3 & -1.92993 \\
\hline
\end{tabular}

From Table 6 it is observed that third concept of the fourth Task contain maximum utility i.e. 5.76244. The levels of attributes for this concept are Qualification: M.Phil., Behavior: Friendly Behavior, Teaching Experience: 4-6 year, Lecture Methodology: Verbal and White Board, Lecture Material: Books and Number of Quizzes: 2 Quizzes. The second highest utility is for the first concept of the fourth Task i.e. -5.45375.The levels of attributes for this concept is Qualification: Behavior: PhD, Teaching Experience: 1-3 years, Lecture Methodology: Multimedia, Lecture Material: Net and Notes, Number of Quizzes: 3 Quizzes.

We find that Attribute "Qualification" is a main key to selection of a teacher for study. On the Basis of individual and average highest utilities the qualification "M. Phil." is most preferred. We conclude that when a student selects a teacher, he/she keep three main points Qualification, Lecture Methodology and Behavior of Teacher in his mind from all six.

\section{CONCLUSION}

Several shortcomings of this survey need to be noted. First, the findings and recommendations could have limited generalizability to other universities because they were based on data collected from only one university. Still, it should be stressed that the university is representative of many other comprehensive large public universities across the nation. This study is beneficial for faculty development program of every university especially University of Gujrat. It is also very important for teaching that how can they satisfy the students and what factors behind student's satisfaction. This paper proposes Conjoint Analysis as a rigorous survey technique for eliciting the views of students.We apply Full Profile Conjoint Analysis and we conclude that students give first importance to qualification, almost same importance to methodology and lecture material. They give least importance to gender of faculty member. Students desire to study from M.Phil. $\backslash \mathrm{PhD}$ female faculty member. She delivers her lecture verbally and with the help of white board and she provides notes to the students on study topic.

From Choice-Based Conjoint Analysis we conclude that Attribute "Qualification" is most important in all service attributes. So Qualification plays important role for selecting a teacher. Students give second importance to behavior of the teacher with students, third importance to Lecture Methodology, fourth importance to Lecture Material, fifth importance to No. of quizzes and sixth importance to Teaching Experience.

Students give preference to M. Phil. faculty member with 4-6 years of teaching experience and they want friendly behavior from their teacher, because students can share their study problems with their teacher without hesitation. Students want notes from their teacher about their study topic. The teachers should try to use verbal and white Board methodology of conveying lecture and he/she take 2 Quizzes.

\section{REFERENCES}

[1] Aloh, I. L, The role of library in functional literacy education in the society. The Nation Builder, 1988, 50-54.

[2] Nelson, R. J., Dodd, J. M., \& Smith, D. J, Faculty attitudes toward to accommodate students with learning disabilities: A comparison among academic divisions, Journal of Learning Disabilities, 23(3), 1990, 185-189.

[3] Bourke, A. B., Strehorn, K. C., \& Silver, P, Faculty members' provision of instructional accommodations to students with LD. Journal of Learning Disabilities, 33(2), 2000, 26-32.

[4] Denny, G. S., \& Carson, E. K, Perceptions of campus climate for students with disabilities. (Reports-Research/ Technica No. 143). (ERIC Document Reproduction Service No. ED 380929), 1994 
Vogel, S.A., Leyser, Y., Wyland, S., \& Brulle,A, Students with learning disabilities in higher education: Faculty attitude and practices. Learning Disabilities Research and Practice, 14(3), 1999, 173-186.

[5] Leyser, Y, A survey of faculty attitudes and accommodations for students with disabilities. Journal of Postsecondary Education and Disability, 7 (3\&4), 1989, 97-108.

[6] Aksamit, D., Morris, M., \& Leuenberger, J Preparation of student services professionals and faculty for serving learning-disabled college students. Journal of College Student Personnel, 28, 1987, 53-59.

[7] Baggett, D. (1994). A study of faculty awareness of students with disabilities. Paper presented at the annual meeting of the National Association for Developmental Education, Kansas City, MO. (ED 369 208)

[8] Fonosch, G.G., \& Schwab, L. O, Attitudes of selected university faculty members toward disabled students. Journal of College Student Personnel, 22, 1981, 229-235.

[9] Xu, G. and Yuan, Y, Conjoint analysis in pharmaceutical marketing research. Quirk's Marketting research review, 2001.

[10] Hair, J.F., Anderson, R. E., Tatham, R. L. and Black, W. C, Multivariate Data Analysis. 5th Ed. Upper Saddle River, New Jersey. Prentice-Hall International, 1998.

[11] Sudman, S., Blair, E, Marketing Research. Boston. McGraw Hill, 1998.

[12] Kotler, P, Marketing Management. The Millennium Edition, London. Prentice-Hall, 2000.

[13] Churchill, G. and Iacobucci, D, Marketing Research, Methodoligal Foundations. 8th Ed. London. Harcourt Publishing, 2002.

[14] Carroll, J. D. and Paul, E. G, Psychometric Methods in Marketing Research: Part 1, Conjoint Analysis, Journal of Marketing Research, 32(11), 1995, 385-391. 